\title{
Oral Susceptibility to Yellow Fever Virus of Aedes aegypti from Brazil
}

\author{
Ricardo Lourenço-de-Oliveira+, Marie Vazeille"*:, Ana Maria Bispo de Filippis*, \\ Anna-Bella Failloux
}

\begin{abstract}
Laboratório de Transmissores de Hematozoários, Departamento de Entomologia *Laboratório de Flavivírus, Departamento de Virologia, Instituto Oswaldo Cruz-Fiocruz, Av. Brasil 4365, 21045-900 Rio de Janeiro, RJ, Brasil **Unité d'Ecologie des

Systèmes Vectoriels, Institut Pasteur, Paris Cedex 15, France
\end{abstract}

The oral susceptibility to yellow fever virus was evaluated in 23 Aedes aegypti samples from Brazil. Six Ae. aegypti samples from Africa, America and Asia were also tested for comparison. Mosquito samples from Asia showed the highest infection rates. Infection rates for the Brazilian Ae. aegypti reached $48.6 \%$, but were under $13 \%$ in $60 \%$ of sample tested. We concluded that although the low infection rates estimated for some Brazilian mosquito samples may not favor the establishment of urban cycle of yellow fever in some parts of the country, the founding of Ae. aegypti of noteworthy susceptibility to the virus in cities located in endemic and transition areas of sylvatic yellow fever, do pose a threat of the re-emergence of the urban transmission of the disease in Brazil.

Key words: susceptibility - Aedes aegypty - yellow fever

In Brazil, urban yellow fever (YF) transmission has not been noticed since 1942 (Franco 1969). During the last 60 years, the reported human YF cases or small outbreaks have been only due to infections acquired inside or close to the jungle, where the virus is transmitted by sylvatic mosquitoes belonging to genera Haemagogus and Sabethes. The urban mosquito vector Aedes aegypti, eradicated from Brazil in the 50's and re-introduced in the 70 's, has been spreading over the country during the following decades, colonizing counties located in the sylvatic YF endemic area. The presence of Ae. aegypti in cities near the YF sylvatic transmission and the possibility of infected people, especially tourists, to move during incubation and viraemia periods to cities highly infested by Ae. aegypti increase chances of contact between this mosquito and YF virus and the risk of urban transmission of the disease in Brazil and other South American countries (Vasconcelos et al. 1999, 2001, Forattini 1999, Prata 2000). Although infected people may be bitten by $A e$. aegypti, urban YF cycle has surprisingly not yet been established in Brazil. However, in Santa Cruz, Bolivia, where Ae. aegypti is present in cities near areas where sylvatic YF is endemic, an outbreak of urban YF has recently been reported. This outbreak was fortunately limited in time and space by vaccination campaigns of urban residents (Van der Stuyft et al. 1999).

This work was supported by $\mathrm{CNPq}$ and US National Institute of Health grant AI-47793.

${ }^{+}$Corresponding author. Fax: + 55-21-2573.4468. E-mail: lourenco@ioc.fiocruz.br

Received 1 February 2002

Accepted 5 March 2002
The oral susceptibility of Ae. aegypti populations to YF virus is one of the important components which can give an insight on the epidemic risk in the re-emergence of the urban transmission of the disease. The determination of the oral susceptibility to YF virus of Ae. aegypti in Brazil has been claimed (Vasconcelos et al. 1999, Prata 2000).

In this study, the oral susceptibility to YF virus of 23 Brazilian samples of Ae. aegypti was evaluated (Table). For comparative purposes, six additional samples from Southeast Asia, West Africa and North and South America were tested. All the Ae. aegypti samples belonged to the pale form (Ae. aegypti aegypti), except for the Boulbinet sample, from Guinea, which corresponded to the dark form, Ae. aegypti formosus. In all essays, the Paea strain of Ae. aegypti collected in Tahiti (Vazeille-Falcoz et al. 1999) was used as control.

Mosquito samples were collected by using ovitraps settled around human dwellings, from March to December 2001, except for the West Palm Beach, Ho Chi Minh, Phnom Penh and Boulbinet samples which were collected either as larvae and/or pupae. Field collected mosquitoes $\left(\mathrm{F}_{0}\right)$ raised to adult in the laboratory were morphologically identified to species and fed on guinea pigs to obtain eggs. The procedures to maintain and infect mosquitoes followed those described by Vazeille-Falcoz et al. (1999).

The YF virus strain (FIOCRUZ 74018/MG/01) was isolated, in Ae. albopictus $\mathrm{C} 6 / 36$ cells, from the serum of a 39-years old human YF fatal case from Bom Despacho, State of Minas Gerais, Brazil, in 2001. It was identified by indirect immunofluorescence (IFA) using anti-YF monoclonal antibodies (CDC\#M20958) and genotyped as American genotype I by partial nucleotide sequencing. Mosquito oral infections were performed with a viral stock corresponding to the supernatant fluid of the 4th pas- 
sage of this virus strain in $\mathrm{C} 6 / 36$ cells. Viral stock production was done according to Vazeille-Falcoz et al. (1999) and titers calculated by the $50 \%$ endpoint method described by Reed and Muench (1938) and expressed as $50 \%$ mosquito infectious doses $\left(\mathrm{MID}_{50}\right) / \mathrm{ml}$.

All infection experiments were conducted with 5- to 7day old $F_{1}$ females fed for 15 min through a chicken skin membrane covering an apparatus containing the infectious meal, composed of $2 / 3$ washed rabbit erythrocytes, $1 / 3$ of YF virus suspension, and ATP $\left(5 \times 10^{-3} \mathrm{M}\right)$. The titer of the meal was $10^{8.7} \mathrm{MID}_{50} / \mathrm{ml}$. Only fully engorged females were considered. Mosquito infection was determined by the detection of YF viral antigen by IFA on head squashes after 14 days of incubation at $28 \pm 1^{\circ} \mathrm{C}$. Statisti-

TABLE

Geographic origin and infection rates in crescent order of Aedes aegypti samples, 14 days after taking an infectious meal with yellow fever virus

\begin{tabular}{|c|c|c|c|c|}
\hline \multicolumn{2}{|l|}{ Locality } & $\begin{array}{l}\text { Region } \\
\text { /State }\end{array}$ & $\begin{array}{c}\% \text { of infected } \\
\text { females } b\end{array}$ & $\mathrm{~N}$ \\
\hline \multicolumn{5}{|l|}{ Brazil } \\
\hline \multicolumn{2}{|l|}{ Milhã } & $\mathrm{NE} / \mathrm{CE}$ & 0 & 148 \\
\hline \multicolumn{2}{|c|}{ Comendador Soares } & $\mathrm{SE} / \mathrm{RJ}$ & 0.9 & 110 \\
\hline \multicolumn{2}{|c|}{ Quixeramobim } & NE/CE & 1.7 & 120 \\
\hline \multicolumn{2}{|c|}{ Rocinha } & $\mathrm{SE} / \mathrm{RJ}$ & 3.3 & 121 \\
\hline \multicolumn{2}{|l|}{ Tinguá } & $\mathrm{SE} / \mathrm{RJ}$ & 4.9 & 103 \\
\hline \multicolumn{2}{|l|}{ Pacujá } & $\mathrm{NE} / \mathrm{CE}$ & 5.6 & 71 \\
\hline \multicolumn{2}{|c|}{ Salvador } & $\mathrm{NE} / \mathrm{BA}$ & 6.3 & 111 \\
\hline \multicolumn{2}{|c|}{ Higienópolis } & $\mathrm{SE} / \mathrm{RJ}$ & 6.7 & 120 \\
\hline \multicolumn{2}{|c|}{ Moquetá } & SE/RJ & 7.6 & 118 \\
\hline \multicolumn{2}{|c|}{ Feira de Santana } & NE/BA & 10.6 & 47 \\
\hline \multicolumn{2}{|c|}{ Rio Branco $^{c}$} & $\mathrm{NO} / \mathrm{AC}$ & 11.1 & 117 \\
\hline \multicolumn{2}{|c|}{ Leandro Ferreira $^{d}$} & SE/MG & 12.0 & 108 \\
\hline \multicolumn{2}{|c|}{ Cariacica } & $\mathrm{SE} / \mathrm{ES}$ & 12.6 & 119 \\
\hline \multicolumn{2}{|l|}{ Boa Vista $^{c}$} & $\mathrm{NO} / \mathrm{RR}$ & 12.9 & 116 \\
\hline \multicolumn{2}{|c|}{ Represa do Cigano } & $\mathrm{SE} / \mathrm{RJ}$ & 16.1 & 56 \\
\hline \multicolumn{2}{|c|}{ São Luis ${ }^{c}$} & $\mathrm{NE} / \mathrm{MA}$ & 19.6 & 112 \\
\hline \multicolumn{2}{|c|}{ Maringád } & $\mathrm{SO} / \mathrm{PR}$ & 22.7 & 119 \\
\hline \multicolumn{2}{|c|}{ Porto Velho ${ }^{c}$} & $\mathrm{NO} / \mathrm{RO}$ & 24.4 & 119 \\
\hline \multicolumn{2}{|c|}{ Campo Grande ${ }^{c}$} & $\mathrm{CW} / \mathrm{MS}$ & 25 & 104 \\
\hline \multicolumn{2}{|c|}{ Potim } & SE/SP & 27.1 & 118 \\
\hline \multicolumn{2}{|c|}{ Belém $^{c}$} & $\mathrm{NO} / \mathrm{PA}$ & 33.9 & 109 \\
\hline \multicolumn{2}{|c|}{ Ananindeua $^{c}$} & NO/PA & 46.4 & 112 \\
\hline \multicolumn{2}{|c|}{ Foz do Iguaçu $d$} & $\mathrm{SO} / \mathrm{PR}$ & 48.6 & 109 \\
\hline \\
\hline \multicolumn{5}{|c|}{$\begin{array}{l}\text { Other countries } \\
\text { Cambodia Phnom Penh }\end{array}$} \\
\hline \multirow[t]{2}{*}{ Vietnam } & Ho Chi Minh ANH14 & ANH14 & 49.1 & 57 \\
\hline & \multicolumn{2}{|c|}{ Ho Chi Minh MIN15 } & 47.0 & 66 \\
\hline Venezuela & \multicolumn{2}{|c|}{ Maracay } & 13.6 & 132 \\
\hline USA & West & ach & 24.8 & 105 \\
\hline Guinea & Boul & & 3.3 & 123 \\
\hline
\end{tabular}

$a$ : regions: $\mathrm{CW}=$ Centre-West; $\mathrm{NE}=$ Northeast $\mathrm{NO}=$ North, $\mathrm{SE}=$ Southeast $\mathrm{SO}=$ South . States: $\mathrm{AC}=$ Acre, $\mathrm{BA}=\mathrm{Bahia}, \mathrm{CE}$ = Ceará, $\mathrm{ES}=$ Espírito Santo, $\mathrm{MG}=$ Minas Gerais, $\mathrm{MS}=$ Mato Grosso do Sul, PA = Pará, PR = Paraná, RJ = Rio de Janeio, RO $=$ Rondônia, $\mathrm{RR}=$ Roraima, $\mathrm{SP}=$ São Paulo, $\mathrm{MA}=$ Maranhão; $b$ : infected mosquitoes are those with YF viral antigen in head tissues; $\mathrm{N}=$ number of examined females; $c, d$ : located in endemic and transition areas of sylvatic $\mathrm{YF}$, respectively; remaining Brazilian localities are in indene areas; $e$ : dark form (Ae. aegypti formosus) cal analysis was performed using $\mathrm{R} \times \mathrm{C}$ Fisher's exact test. A total of 2,487 Ae. aegypti from Brazil were tested. Except for Ae. aegypti collected in Milhã, which 148 tested females were negative, all other evaluated Ae. aegypti samples from Brazil were orally susceptible to YF virus. However, the infection rates were heterogeneous when all Brazilian samples were considered $(P<0.05)$. In the great majority of the Brazilian Ae. aegypti samples (14 out of 23) infection rates were low, i.e. under $13 \%$. This was the case of most of Ae. aegypti samples from Northeast (Pacujá, Quixeramobim, Salvador, Feira de Santana) and Southeast regions (Cariacica, Leandro Ferreira and five samples from the State of Rio de Janeiro). Actually, we can consider that the vectorial competence of these samples is low, even though YF infected mosquitoes have not been tested for experimental transmission. On the other hand, when only samples from the endemic area of sylvatic YF transmission (Table) were taken into account, the infection rates were higher, although heterogeneous $(P<0.05)$, ranging from $11.1 \%$ in Rio Branco to $46.4 \%$ in Ananindeua. The highest infection rate for Ae. aegypti was observed for Foz do Iguaçu (48.6\%), which is located in the transition area of sylvatic YF transmission in Brazil. The Asian samples were more susceptible (47\%-64.4\%) than those from Brazil (0-48.6\%), Venezuela (13.6\%) and USA (24.8\%). Only $3.3 \%$ of mosquitoes from the dark form Ae. aegypti formosus (Boulbinet) became infected with YF virus. The infection rates for the Paea control strain ranged from $30 \%$ to $56 \%$.

This is the first time the YF infection rates of $A e$. aegypti samples from Brazil were experimentally evaluated. Before Ae. aegypti eradication, several experiments of YF transmission were conducted with this mosquito collected in Brazil (Strode 1951), but the proportions of susceptible females per infected lots were unknown.

The low oral susceptibility to YF virus of most of the Brazilian Ae. aegypti samples we tested certainly contributes to the absence of the urban transmission in the country. For example, the municipality of Leandro Ferreira experienced an outbreak of sylvatic YF in 2001. The locality although infested by Ae. aegypti did not undergo urban transmission of YF. Our results showed that only $12 \%$ of the Ae. aegypti females from this small city became infected with the YF strain isolated from a man infected in the neighboring forest. Low susceptibility of Ae. aegypti to the virus may limit the occurrence of a YF urban cycle there. This was the case of the Guinean situation: in Sep. 2001, few YF human cases were suspected and only two were laboratory confirmed in Boulbinet. Despite of the presence of Ae. aegypti, no outbreak was reported (A Yebakina, pers. commun.). Coincidently, our results showed that the Boulbinet sample presented a low infection rate for YF virus (3.3\%). Besides oral susceptibility, other factors must be considered to explain the restriction of transmission to the sylvatic cycle in Brazil. Low oral susceptibility to YF virus certainly tends to limit the dissemination of the infection into urban areas but alone does not explain why urban transmission has not been initiated from sylvan outbreaks around Ae. aegypti infested cities such as Leandro Ferreira. Besides low susceptibility, perhaps the density of Ae. aegypti in such 
small cities is not enough for initiating an YF transmission cycle. Actually, it has been shown that Ae. aegypti populations with a relatively low susceptibility to YF virus may be involved in the occurrence of outbreaks. In 1987, Nigeria experienced a large urban YF epidemic transmitted by Ae. aegypti that showed low oral susceptibility: $26 \%$ became experimentally infected and only $7 \%$ succeeded in transmitting YF virus. On the other hand, Ae. aegypti was present in extremely large numbers in both domestic and peri-domestic environments during the outbreak (Miller et al. 1989).

A high oral susceptibility to YF virus in Ae. aegypti does not account for the presence of transmission. Indeed, YF outbreak has never been reported in Asia although the Ae. aegypti samples tested herein from Cambodia and Vietnam were the most susceptible. Ae. aegypti samples from Ananindeua and Foz do Iguaçu, located respectively in the endemic and transition areas of sylvatic YF transmission, were considerably susceptible to YF virus ( $>45 \%$ positive), even though urban transmission has not been reported there.

The question raised is to know if the current $A e$. aegypti Brazilian populations have lower vectorial competency compared to populations present in the country before the eradication. It has been wondered if the country was re-colonized by populations imported from YFfree areas where mosquitoes were weakly susceptible to the virus, resulting in the absence of urban YF transmission (Prata 2000). Actually, even before Ae. aegypti and urban YF eradication in Brazil, the frequency which YF outbreaks disseminated from jungles into urban centers was much lower than expected, as stressed by Whitman and Antunes (1938). No comparison of the oral susceptibility to YF virus between the ancient and present $A e$. aegypti Brazilian populations is feasible. It is possible that the Brazilian Ae. aegypti populations are derived from founders coming from different parts of the World, and probably from the American countries where the species has never been eradicated, such as Venezuela and USA. We tested samples from Maracay, Venezuela, and West Palm Beach, USA, whose infection rates (13.6\% and 24.8\%, respectively) were similar to those estimated for most of the Brazilian ones.

The determination of oral susceptibility of Brazilian Ae. aegypti is an essential information lacking in the evaluation of the risk of YF urbanization in the country. Other components determining the vectorial capacity, such as mosquito density, daily survivorship, dispersal, and biting rate, as well as the duration of viraemia and the immune background of human population must be taken into account for the understanding of the absence of urban YF transmission in Brazil where high infestation by Ae. aegypti is reported. Nowadays, a low YF immunization coverage and the presence of Ae. aegypti of noteworthy susceptibility to YF virus near endemic areas of sylvatic YF, such as Belém, Ananindeua and Foz do Iguaçu, increase the risk of urban outbreaks. In addition, the possibilities of rapid displacement of infected people from YF sylvatic endemic areas to densely populated cities with high Ae. aegypti infestation, still pose a threat of the re-emergence of the urban transmission of the disease in Brazil

Further studies on oral susceptibility to YF virus as well as on genetic structure of Ae. aegypti Brazilian populations are necessary in order to access mosquito dispersal and thus, gene flow between populations. Selected genes such as those controlling the vector capacity could be disseminated depending on environmental factors and human activities facilitating mosquito and virus spreading.

\section{ACKNOWLEDGMENTS}

To Nadia Monnier and Catherine Thouvenot for the help in the rearing of mosquitoes; to Dr Hermann Gonçalves Schatzmayr and Dr Rita Maria Ribeiro Nogueira for providing the YF virus isolate; to Milena Mazzarri, Fátima dos Santos, Nildimar Honório, Durval Bertran, Ducineia Barros, Pedro M Silva, Fernanda LP da Silva, Adão Pereira, Valdecir Nunes, Denilson Santos, Welington C Silva, Paulo J Leite, José Reinaldo Moreira, Uranius Assumpção, Manoel Araújo, Marcelo Carvalho, Gisela Marques, Silvia Ahid, Mariângela Ziccardi, Monique Motta, Márcia G Castro, Maria Goreti Rosa-Freitas, Ana Cláudia Regazzi, Lindembergh C de Sousa, Helder Resende, Claucio de Moraes, Marcelo Quintela, Allan M. Silva, Marieta Braks, Richar Escher, L P Lounibous, Christophe Paupy, Luu Le Loan and André Yebakina for their assistance in collecting mosquito samples.

\section{REFERENCES}

Forattini OP 1999. Febre amarela. Rev Saúde Públ 33(6): Editorial.

Franco O 1969. História da Febre Amarela no Brasil, Ministério da Saúde, DNERU, Rio de Janeiro, 208 pp.

Miller BR, Monath TP, Tabachnick WJ, Ezike VI 1989. Epidemic yellow fever caused by an incompetent mosquito vector. Trop Med Parasitol 40: 396-399.

Prata A 2000. Yellow fever. Mem Inst Oswaldo Cruz 95 (Suppl. I): 183-187.

Reed LJ, Muench H 1938. A simple method of estimation fifty per cent endpoints. Am J Hyg 27: 493-497.

Strode GK 1951. Yellow Fever, Mc Graw-Hill, New York, 710 pp.

Van der Stuyft P, Gianell A, Pirard M, Cespedes J, Lora J, Peredo C, Pelegrino JL, Vorndam V, Boelaert M 1999. Urbanization of yellow fever in Santa Cruz, Bolivia. Lancet 353: 1558-1562.

Vasconcelos PFC, Costa ZG, Travassos-da-Rosa ES, Luna E, Rodrigues SG, Barros VLRS, Dias JP, Monteiro HAO, Oliva OFP, Vasconcelos HB, Oliveira RC, Sousa MRS, Barbosa da Silva J, Cruz ACR, Martins EC, Travassos-da-Rosa JFS 2001. Epidemic of jungle yellow fever in Brazil, 2000: implications of climatic alterations in disease spread. $J$ Med Virol 65: 598-604.

Vasconcelos PFC, Travassos-da-Rosa APA, Pinheiro FP, Rodrigues SG, Travassos-da-Rosa ES, Cruz ACR, Travassos-da-Rosa JFS 1999. Aedes aegypti, dengue and re-urbanization of yellow fever in Brazil and other South American countries - Past and present situation and future perspectives. Dengue Bull 23: 55-66.

Vazeille-Falcoz M, Mousson L, Rodhain F, Chungu E, Failloux AB 1999. Variation in oral susceptibility to dengue type 2 virus of populations of Aedes aegypti from the islands of Tahiti and Moorea, French Polynesia. Am J Trop Med Hyg 60: 292-299.

Whitman L, Antunes PCA 1938. The transmission of two strains of jungle yellow fever virus by Aedes aegypti. Am J Trop Med 18: 135-147. 